OPEN ACCESS

Edited by:

Katell Quenea,

Sorbonne Universités, France

Reviewed by:

Rota Wagai,

National Agriculture and Food Research Organization (NARO), Japan Wenting Feng,

Institute of Agricultural Resources and Regional Planning (CAAS), China

*Correspondence: Christopher Just c.henke@tum.de

TORCID:

Christopher Just 0000-0001-9727-5470

Christopher Poeplau 0000-0003-3108-8810

Axel Don

0000-0001-7046-3332

Bas van Wesemael 0000-0003-4007-0241

Ingrid Kögel-Knabner 0000-0002-7216-8326

Martin Wiesmeier

0000-0003-3981-5461

Specialty section:

This article was submitted to Soil Organic Matter Dynamics and

Carbon Sequestration,

a section of the journal

Frontiers in Soil Science

Received: 04 August 2021 Accepted: 03 September 2021

Published: 08 October 2021

Citation:

Just $C$, Poeplau C, Don A, van Wesemael B, Kögel-Knabner I and

Wiesmeier M (2021) A Simple Approach to Isolate Slow and Fast Cycling Organic Carbon Fractions in Central European Soils - Importance of Dispersion Method.

Front. Soil Sci. 1:692583.

doi: 10.3389/fsoil.2021.692583

\section{A Simple Approach to Isolate Slow and Fast Cycling Organic Carbon Fractions in Central European Soils-Importance of Dispersion Method}

\author{
Christopher Just ${ }^{1 \star \dagger}$, Christopher Poeplau ${ }^{2 \dagger}$, Axel Don ${ }^{2 \dagger}$, Bas van Wesemael ${ }^{3 \dagger}$, \\ Ingrid Kögel-Knabner ${ }^{1,4 \dagger}$ and Martin Wiesmeier ${ }^{1,5+}$ \\ ${ }^{1}$ Soil Science, TUM School of Life Sciences Weihenstephan, Technical University of Munich, Munich, Germany, ${ }^{2}$ Thünen \\ Institute of Climate-Smart Agriculture, Braunschweig, Germany, ${ }^{3}$ Georges Lemaitre Centre for Earth and Climate \\ Research-Earth and Life Institute, Université Catholique de Louvain, Ottignies-Louvain-la-Neuve, Belgium, ${ }^{4}$ Institute for \\ Advanced Study, Technical University of Munich, Munich, Germany, ${ }^{5}$ Bavarian State Research Center for Agriculture, \\ Institute for Organic Farming, Soil and Resource Management, Freising, Germany
}

Numerous approaches have been developed to isolate fast and slow cycling soil organic carbon (SOC) pools using physical and chemical fractionation. Most of these methods are complex, expensive, and time consuming and unsuited for high-throughput application, such as for regional scale assessments. For simpler and faster fractionation via particle size the key issue is the dispersion of soil. It is unclear how the initial dispersion of soil affects the turnover rates of isolated fractions. We investigated five commonly used dispersion methods using different intensities: shaking in water, shaking in water with glass beads, ultrasonication at 100 and $450 \mathrm{~J} \mathrm{ml}^{-1}$ and sodium hexametaphosphate (Na-HMP). We used soils from long-term field experiments that included a change from C3 to $\mathrm{C} 4$ vegetation and adjacent control sites using $\delta^{13} \mathrm{C}$ isotope ratio mass spectrometry. We evaluated the degree of $\mathrm{C} 3 / \mathrm{C} 4$ moieties of the fractions, mass and carbon recovery and reproducibility as well as the time expenditures of the dispersions, sieving and drying techniques to develop an efficient and cheap fractionation method. Our results indicate that ultrasonication as well as $\mathrm{H}_{2} \mathrm{O}$ treatment with and without glass beads resulted in fractions with different turnover. Moreover, isolation performances depended on soil texture. While the isolation of the fractions using water with and without glass beads was equivalent to ultrasonication in soils with low clay contents, these methods had limited potential for soils with high clay contents. Furthermore, treatment with water alone had less reproducible results than other tested methods. The SOC recovery was comparable and satisfactory amongst non-chemical dispersion methods and reached over $95 \%$ for each of these methods. The use of Na-HMP was unsuccessful due to high time expenditures and strong SOC leaching. We propose particle size fractionation combined with ultrasonic dispersion as a fast and highly reliable method to quantify slow and fast cycling SOC pools for a wide range of soil types and textures from agricultural sites in central Europe.

Keywords: soil organic carbon, carbon sequestration, soil fractions, agricultural soils, particulate organic matter, mineral-associated organic matter 


\section{INTRODUCTION}

Soil organic matter (SOM) plays an important role influencing soil functions and the global carbon cycle (1). It determines the nutrient cycle when it is decomposed and can also withdraw carbon (C) from the atmosphere and sequester it in the soil for long periods $(2,3)$. It is estimated that SOM stores two to three times as much $\mathrm{C}$ as the atmosphere (4). Different soil management practices strongly affect SOC stocks and appropriate soil management has the potential to improve nutrient availability and $\mathrm{C}$ sequestration $(5,6)$.

Physical and chemical fractionation methods are used to differentiate between functional SOC fractions containing SOC pools with different turnover times. Physical fractionation methods can be roughly categorized into aggregate and particle fractionations (7-9). Aggregate and particle fractionations isolate fractions by size, density or a mixture of both. Aggregate fractionations are mostly used to explore the influences of management practices on the ecosystem functions of soil aggregates, e.g., their respective pore spaces and microbial habitats (10-12). However, particle fractionations are based on the assumption that the associations between soil particles and their spatial arrangement are important for SOM dynamics because their bioaccessibility is a major driver of SOM decomposition (13). Therefore, particle fractionation methods are mostly used to isolate organic matter $(\mathrm{OM})$ fractions with different turnover times $(9,14,15)$. Particle density fractionation is applied to separate SOM that is not firmly associated with soil minerals. These light fractions (LFs) consist of plant residues that are either free in the soil matrix or occluded in particles $(13,15)$. Particle size fractionation is based on the concept, that decay induces fragmentation and $\mathrm{OM}$ formed during decomposition associates with minerals, preventing further decay $(9,13)$. Particle density fractionations are often combined with particle size fractionations in fractionation schemes to collect additional information on LFs (16-18). While density fractionations allow a more differentiated separation of heavy and light fractions, simple particle size fractionations can be conducted faster and cheaper $(8,9,13,14,19-24)$.

In this regard, two fractions are most often considered: mineral-associated organic matter (MAOM), which can be assigned to different particle size classes of $<20 /<50 /<63 \mu \mathrm{m}$, and particulate organic matter (POM), which is assigned to coarser particle size above these thresholds (25-27). The MAOM fraction is protected from biological decomposition by its binding to the mineral phase and has long mean residence times in the magnitude of decades to millennia $(14,28)$. However, the POM fraction is less protected from degradation and has short residence times (28-30). Therefore, MAOM fractions are suitable as indicators for SOC sequestration $(14,21)$, and POM fractions can be used to assess the of direct impacts of agricultural soil management on SOC content on a decadal timescale (31).

Methods for estimating the SOC storage potential of soils have emerged from the quantification of these two fractions, including the OC saturation concept $(21,32-34)$ and modelbased concepts (35-37). For both concepts, measurements of POM and MAOM are needed. The substantial diversity of fractionation methods and their often time-consuming procedures calls for the development of simplified fractionation schemes (27). Poeplau et al. (24) used a large-scale approach to compare the isolation quality, time required and costs of different fractionation methods. Their results confirmed that the simple separation of silt and clay from sand-sized fractions provides strong contrasts in turnover rates. Therefore, simple separation of silt-, sand-, and clay-sized fractions is similarly successful at isolating SOC pools with distinct properties as much more complex methods using density fractionation, and it is faster.

All particle size fractionation protocols involve procedures that disperse soil aggregates, making them different from aggregate size fractionation protocols. However, little is known about the effect of different soil dispersion approaches on the isolation efficiency of distinct soil carbon fractions. Prevalent dispersion approaches are least destructive pre-treatments with water, sometimes with physically disruptive bodies such as glass beads $(19,38-40)$, the use of ultrasound (41-43), and treatment with chemical dispersants to peptize soil (44-46). In particular, ultrasonication at different intensities has received increasing attention over the past few decades. However, there were indications that the results were not comparable between laboratories. Such laboratory bias could be reduced when parameters are kept constant (47).

In this study, we evaluated a simplified fractionation scheme that allows the quantification of fast- and slow-cycling SOC pools for a wide range of soils considering time requirements and cost efficiency. Since soil dispersion is one of the key steps of particle size fractionation methods and it is still unclear which dispersion is best suited for large-scale data acquisition of POM and MAOM, the final aim of this study was to investigate and quantify the performance of various dispersion approaches for a particle size fractionation method $(>20 /<20 \mu \mathrm{m})$. Dispersion efficiency was evaluated based on the separation of young and old SOC after C3 and C4 vegetation changes estimated via ${ }^{13} \mathrm{C}$ natural abundance measurements. The experiment was conducted on soils from five long-term field experiments in central Europe with a range in texture and SOC content. In addition to natural abundance measurements, further indicators with regard of recovery and mass balance, reproducibility and labor costs were used for the entire fractionation process, and subdivided into the fractionation modules dispersion, wet sieving and drying.

\section{MATERIALS AND METHODS}

\section{Experimental Sites and Soil Collection}

We used five different soils from long-term field experiments (LTEs) in central Europe: Braunschweig (Bs), Hohenheim (Ho), Jyndevat (Jy), Rotthalmünster (Ro), and Tänikon (Ta) (Table 1). The experimental design included fields that had undergone a shift from C3 to C4 vegetation and adjacent control plots that were exclusively cultivated with C3 crops.

All LTEs were chosen with a focus on sampling a variety of soil types and a gradient in soil texture to create a dataset representative of central European soils. Soil clay contents ranged from $4 \%$ in Braunschweig to $29 \%$ in Tänikon, and silt contents 
TABLE 1 | Details of the five experimental sites: Mean annual temperature (MAT), mean annual precipitation (MAP), soil organic carbon content of C3 reference soil $\left(\mathrm{SOC}_{\mathrm{C} 3}\right)$ and the $\mathrm{C} 4$ soil $\left(\mathrm{SOC}_{\mathrm{C} 4}\right)$, proportions of sand, silt and clay, soil $\mathrm{pH}\left(\mathrm{H}_{2} \mathrm{O}\right)$, years under $\mathrm{C} 4$ vegetation, $\mathrm{C} 4$ plant species, $\delta 13 \mathrm{C}$ signatures of $\mathrm{C} 3$ and $\mathrm{C} 4 \mathrm{soil}$, and the proportion of $\mathrm{C} 4$-derived $\mathrm{C}(\mathrm{fC} 4)$ in the bulk soil.

\begin{tabular}{|c|c|c|c|c|c|c|c|c|c|c|c|c|c|}
\hline Experimental site & ID & $\begin{array}{l}\text { MAT } \\
{\left[{ }^{\circ} \mathrm{C}\right]}\end{array}$ & $\begin{array}{l}\text { MAP } \\
{[\mathrm{mm}]}\end{array}$ & $\begin{array}{l}\text { Soil type } \\
\text { (WRB) }\end{array}$ & $\begin{array}{c}\mathrm{SOC}_{\mathrm{C} 3} \\
{[\mathrm{mg}} \\
\left.\mathrm{g}^{-1}\right]\end{array}$ & $\begin{array}{c}\mathrm{SOC}_{\mathrm{c} 4} \\
{[\mathrm{mg}} \\
\left.\mathrm{g}^{-1}\right]\end{array}$ & $\begin{array}{c}\text { Sand/silt/clay } \\
{[\%]}\end{array}$ & $\mathrm{pH}$ & Years under C4 & C4 plant & $\begin{array}{c}\delta^{13} \mathrm{C}_{\mathrm{C} 3} \text { bulk } \\
\text { soil } \\
\text { [\%o VPDB] }\end{array}$ & $\begin{array}{c}\delta^{13} \mathrm{C}_{\mathrm{C} 4} \text { bulk } \\
\text { soil } \\
{[\% \text { VPDB] }}\end{array}$ & $\mathbf{f}_{\mathrm{C} 4}$ \\
\hline Braunschweig & Bs & 8.8 & 620 & Cambisol & 18.4 & 17.4 & $67 / 29 / 4$ & 6.2 & 22 & Miscanthus & -28.1 & -19.4 & 0.54 \\
\hline Hohenheim & $\mathrm{Ho}$ & 8.7 & 679 & Luvisol & 79.9 & 58.0 & $36 / 54 / 10$ & 7 & 21 & Miscanthus & -26.8 & -19.7 & 0.48 \\
\hline Jyndevad & Jy & 7.9 & 859 & Arenosol & 18.7 & 21.7 & $91 / 6 / 3$ & 5.1 & 18 & Miscanthus & -27.8 & -24.9 & 0.18 \\
\hline Rotthalmünster & $\mathrm{Rt}$ & 8.7 & 886 & Luvisol & 14.1 & 13.5 & $17 / 75 / 8$ & 6.2 & 36 & Maize/Sorghum & -27.4 & -21.5 & 0.38 \\
\hline Tänikon & $\mathrm{Ta}$ & 8.4 & 1,185 & Luvisol & 19.5 & 33.2 & $39 / 32 / 29$ & 7.1 & 17 & Miscanthus & -26.9 & -21.0 & 0.40 \\
\hline
\end{tabular}

ranged from $6 \%$ in Jyndevad to $75 \%$ in Rotthalmünster (Table 1). Mean annual temperatures were typical for temperate regions in central Europe ranging between $7.9^{\circ} \mathrm{C}$ in Jyndevad to $8.8^{\circ} \mathrm{C}$ in Braunschweig, whereas the mean annual precipitation was more diverse and ranged from $620 \mathrm{~mm}$ in Braunschweig to $1,185 \mathrm{~mm}$ in Tänikon. The SOC contents ranged from $14 \mathrm{mg}$ $\mathrm{g}^{-1}$ in Rotthalmünster, $18 \mathrm{mg} \mathrm{g}^{-1}$ in Braunschweig, $20 \mathrm{mg} \mathrm{g}^{-1}$ in Jyndevad, and $19 \mathrm{mg} \mathrm{g}^{-1}$ (C3-site) to $34 \mathrm{mg} \mathrm{g}^{-1}$ (C4-site) in Tänikon. The SOC contents in Hohenheim were considerably higher than at the other sites due to its grassland history with approximately $80 \mathrm{mg} \mathrm{g}^{-1}$ (C3-site) and $58 \mathrm{mg} \mathrm{g}^{-1}$ (C4site). Four out of five experimental sites were cultivated with the C4-plant Miscanthus x giganteus. The experimental site in Rotthalmünster was cultivated with the C4-plant Zea mays, and there was intermittent interruption of maize cultivation with millet (Sorghum spec.) in the years 2012 and 2014. The soil samples were collected after 17-36 years of C4/C3 plant cultivation (Table 1) as composite samples on $\sim 300 \mathrm{~m}^{2}$ grids, which were described in (48), within a depth of $10 \mathrm{~cm}$. Then, the samples were oven dried at $60^{\circ} \mathrm{C}$ and sieved to $2 \mathrm{~mm}$.

\section{Soil Fractionation}

All experiments were conducted using $10 \mathrm{~g}$ of dried soil of each sample (Figure 1). We tested and compared the performance of five commonly used dispersion methods at isolating two fractions with distinct SOM turnover times. As we were looking for an approach that can easily be adapted by any laboratory, we tried to minimize complexity and the time and labor requirements. Therefore, we adapted and modified four physical dispersion methods with a gradient in dispersion intensity as follows:

1. Soils shaken in $100 \mathrm{ml}$ of deionized water on a flatbed horizontal shaker for $25 \mathrm{~min}$ at $250 \mathrm{rpm}$ [adapted and modified from van Wesemael et al. (31)] - This method is referred to as " $\mathrm{H}_{2} \mathrm{O}$ "

2. Soils shaken in $100 \mathrm{ml}$ of deionized water on a flatbed horizontal shaker for $25 \mathrm{~min}$ at $250 \mathrm{rpm}$ in presence of 10 glass beads with a diameter of $4 \mathrm{~mm}$ [adapted and modified from Rovira et al. (40) referred to as "Glassbeads"]

3. Ultrasonication (Sonopuls HD2200, Bandelin electronic $\mathrm{GmbH}$, Germany) in $150 \mathrm{ml}$ of deionized water with a low energy input of $100 \mathrm{~J} \mathrm{ml}^{-1}$ (calorimetric calibration)

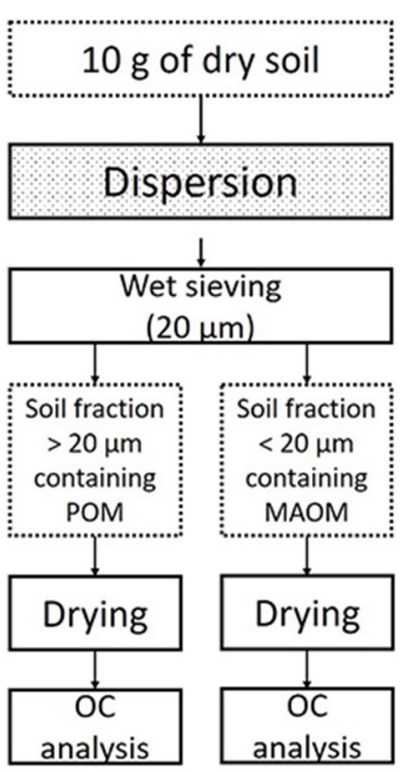

FIGURE 1 | General scheme for a simplified fractionation to separate POM and MAOM with focus on the comparison of different dispersion procedures.

[according to Hassink (21)] with a 13-mm-diameter sonotrode, an oscillation frequency of $20 \mathrm{kHz}$ and an immersion depth of $15 \mathrm{~mm}$ (following Graf-Rosenfellner et al. (47)]-referred to as "US100"

4. Ultrasonication (Sonopuls HD2200, Bandelin electronic $\mathrm{GmbH}$, Germany) in $150 \mathrm{ml}$ deionized water with high energy input of $450 \mathrm{~J} \mathrm{ml}^{-1}$ (calorimetric calibration) [according to Schmidt et al. (49)] with a 13-mm-diameter sonotrode, an oscillation frequency of $20 \mathrm{kHz}$ and an immersion depth of $15 \mathrm{~mm}$ [according to Graf-Rosenfellner et al. (47)]-referred to as "US450".

The initial experimental setup included a fifth dispersion method using sodium-hexametaphosphate (Na-HMP) as a chemical dispersion agent. However, this method was discontinued during the course of the experiment. The data acquired for this method was subsetted and separately evaluated from the other methods. 
5. Chemical dispersion in $40 \mathrm{ml} 0.5 \%$ Sodiumhexametaphosphate $\left(\mathrm{NaPO}_{3}\right)_{6}$ shaken on a flatbed horizontal shaker [following $(14,45,46)]$ referred to as "Na-HMP."

In total, the main dataset (without the Na-HMP treatment) contained $n=80$ samples [five sites $\times$ two vegetation types $(\mathrm{C} 3 / \mathrm{C} 4) \times$ four dispersing methods $\times$ two replications], which were separated into fractions $>20$ and $<20 \mu \mathrm{m}$. The Na-HMP subset consisted of eight samples dispersed with Na-HMP out of one site (Hohenheim C3) for additional analysis. The sieving process was modified from the other studies using this method. All samples were wet sieved using a $20 \mu \mathrm{m}$ stainless steel sieve which was mounted on a horizontal shaking sieving machine (Analysette 03.502, Fritsch $\mathrm{GmbH}$, Germany) with a frequency of $\sim 50 \mathrm{~Hz}$ and an amplitude of $2-3 \mathrm{~mm}$ to standardize the sieving process.

\section{Time Efficiency}

Because time efficiency is of particular interest when working with large sample sets, we successively timed all actions that formed part of the fractionation schemes. We evaluated the time efficiency for all five dispersion methods. Additionally, we measured the time needed for manual wet sieving with a rubber spatula, automated wet sieving, and different drying procedures, including a drying cabinet, freeze dryers or rotary evaporators in a pre-experiment. We classified the required times into an active working time and a total time (comprising active working time and waiting time) needed for all fractionation steps. The measured time periods were averaged for the methods and rounded to $5 \mathrm{~min}$ intervals. A detailed scheme of the fractionation steps can be found in the Supplementary Figure 1.

\section{Determination of $\mathrm{C}$ and $\delta^{13} \mathrm{C}$}

Total carbon (C) was measured in all fractions and bulk samples using dry combustion (HEKAtech EuroEA 3000). The measurement accuracy of the instrument was $2 \mathrm{mg} \mathrm{C} \mathrm{g}^{-1}$ of soil. Total inorganic carbon (IC) was measured upon calcimetric reaction $(4 \mathrm{M} \mathrm{HCl})$. We did not detect inorganic carbon in the samples and total $\mathrm{C}$ was taken as the organic $\mathrm{C}$ concentration. The $\delta^{13} \mathrm{C}$ (VPDB standard) was measured using an isotope ratio mass spectrometer (IRMS) (Delta V Advantage coupled to EA Isolink CN, Thermo Fischer Scientific, Waltham, USA), at the Thünen Institute isotope laboratory. For soils the accuracy of the system is $\delta{ }^{13} \mathrm{C}<0.5 \%$ based on routine analyses. All measurements were performed with at least two replicates, which is usually sufficient to reach the required accuracy as given above. Additional replicates were measured when the difference between the first two replicates reached thresholds of $2 \mathrm{mg} \mathrm{C} \mathrm{g}^{-1}$ soil for total carbon and $0.5 \% \delta^{13} \mathrm{C}$ for IRMS measurements.

\section{Assessment of Performance Indicators}

We assessed the incorporation of new C4-derived C into the fractions by using (19):

$$
f_{C_{\text {fraction }_{i}}}=\frac{\delta^{13} C_{\text {fraction }_{i}(C 4 \text { soil })}-\delta^{13} C_{\text {fraction }_{i}(C 3 \text { soil })}}{\delta^{13} C_{\text {fraction }_{i}(C 4 \text { plant })}-\delta^{13} C_{\text {fraction }_{i}(C 3 \text { soil })}}
$$

where $f_{C 4}$ is the factor of $\mathrm{C} 4$-derived $\mathrm{C}$ in the soil fraction in $_{\mathrm{i}}$ in the C4-vegetated soil and the $\delta^{13} \mathrm{C}$ values of the fraction ${ }_{\mathrm{i}}$ (C4 soil / C3 soil) and $\mathrm{C} 4$ plant refers to the $\delta^{13} \mathrm{C}$ values of the SOC fraction of interest in the $\mathrm{C} 4$ vegetated soil, the same SOC fraction in the $\mathrm{C} 3$ reference soil, and the $\delta^{13} \mathrm{C}$ value of the grown $\mathrm{C} 4$ plant. We fixed the $\delta^{13} \mathrm{C}$ reference value for the $\mathrm{C} 4$ plant at $-12 \%$ (50). Thus, an $f_{C 4}$ of 1 corresponds to a sample or $\mathrm{C}$ fraction, where all $\mathrm{C}$ is new C4-plant derived $\mathrm{C}$, whereas an $f_{\mathrm{C} 4}$ of 0 corresponds to a $\mathrm{C}$ fraction with no input of $\mathrm{C} 4$-plant derived $\mathrm{C}$. We used the range of the $f_{C 4}$ of the two fractions to quantify the degree of isolation for each dispersion treatment described as

$$
\text { Range } f_{C 4}=f_{C 4_{\max }}-f_{C 4_{\min }}
$$

where $f_{C 4_{\max }}$ is the maximum $f_{C 4}$ value of both fractions of a soil while $f_{C 4_{\min }}$ is the minimum value of both fractions of the same soil. As such, Range $f_{C 4}$ was calculated as the mean value for all replicates of a given method. Therefore, a high Range $f_{C 4}$ is an indicator for a well-performing fractionation method, while a low Range $f_{C 4}$ identifies a method that lacks performance in terms of isolating the $\mathrm{C} 4 / \mathrm{C} 3-\mathrm{C}$ derived fractions within a soil (24). Additionally, we evaluated the mass loss/recovery of each method by adding up the mass contributions of the fractions divided by the initial mass of the sample to quantify the loss of soil during the application of our methods. Then. the mass recoveries were averaged for each method. Moreover, we evaluated the reproducibility of the methods by assessing the range of the mass contributions of a fraction between the replicates described as

$$
\begin{aligned}
& \text { Range }_{\text {fraction }_{i}}\left(\text { in } \mathrm{mg}^{-1}\right. \text { soil) } \\
& =\left|\frac{M_{\text {fraction }_{i_{\text {replicate }} 1}} \times 1000}{M_{\text {total }_{i}}}-\frac{M_{\text {replicate 1 }}}{\text { fraction }_{\text {replicate } 2}}\right|
\end{aligned}
$$

where $M$ is the mass of a corresponding fraction f $_{i}$ and/or a given replicate or the total mass of the soil, i.e., the sum of the mass of both fractions of a given replicate, and $|x|$ stands for the mathematical function of absolute values. The Range $_{M}$ was averaged for each method. Therefore, a smaller Range $_{M}$ is an indicator of the reproducibility of the methods, where an increasing value indicates decreasing reproducibility. Additionally, we calculated $\mathrm{C}$ mass recovery and reproducibility by exchanging soil mass with soil $\mathrm{C}$ mass in the former equations.

$$
\begin{aligned}
& \text { Range }_{\text {fraction }_{i}}\left(\text { in } m g g^{-1} C\right)
\end{aligned}
$$

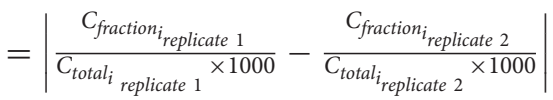

The SOC loss caused by rinsing of the used Na-HMP was evaluated in the Na-HMP sample by comparing the SOC content against an unrinsed control group.

Additionally, we calculated the $2{ }^{13} \mathrm{C}$-recovery as a cross check to verify the consistency and validity of our $\partial^{13} \mathrm{C}$ measurements. The calculation and data can be seen in the Supplementary Material.

\section{Statistical Analysis}

All calculations were performed using the statistical software R. We used Kruskal-Wallis tests and analysis of variance models to 
test for average differences/influences in the Range $\mathrm{fc}_{\mathrm{c} 4}$ between the dispersion methods $\left(\mathrm{H}_{2} \mathrm{O}\right.$, Glassbeads, US100, US450) and the sites for significance at $\mathrm{p}<0.05$. Multiple comparisons were evaluated using the Tukey's Honestly Significance Difference test out of the package "multcomp" (51). Moreover, we applied Fisher's $t$-test to test for mean value differences within the proportions of $\mathrm{C} 4$-derived carbon of the fractions $<20$ and $>20 \mu \mathrm{m}$. The effects of Na-HMP induced SOC leaching were evaluated using Welsh's $t$-test for data with unequal variance. All data were checked for normality and homoscedasticity using a ShapiroWilk test on either the variables or the residues. We used a significance level of $p<0.05$ for all tests.

\section{RESULTS}

\section{C4-Derived Organic Carbon Proportion in Fractions}

The proportion of C4-derived organic carbon was significantly different $(t=5.9508, d f=33.696, p<0.001)$ between the fractions $>20$ and $<20 \mu \mathrm{m}$. Mean C4-derived OC was $26 \%$ in the fraction $<20 \mu \mathrm{m}$ and $54 \%$ in the fraction $>20 \mu \mathrm{m}$ (Figure 2). Mean C4-derived OC was dependent on the dispersion method ranging from 46 and $47 \%$, respectively, for the Glassbeads and $\mathrm{H}_{2} \mathrm{O}$ treatments to 58 and $63 \%$, respectively, for the US100 and US450 treatments in the fraction $>20 \mu \mathrm{m}$. In the fraction $<20 \mu \mathrm{m}$, it ranged from 22 and $23 \%$, respectively, for $\mathrm{H}_{2} \mathrm{O}$ and Glassbeads treatments to 26 and 31\% for the US100 and US450 treatments. Furthermore, despite there being a distinct increase in C4-derived $\mathrm{C}$ in the fractions $>20 \mu \mathrm{m}$, we also measured a slight shift of C4-derived $\mathrm{C}$ into the fractions $<20 \mu \mathrm{m}$ in almost all soils with increasing intensity of the used dispersion methods. The Range $\mathrm{fc}_{\mathrm{f} 4}$ was very constant for the dispersion methods in the soils of Braunschweig $(0.20 \pm 0.01)$, Jyndevad $(0.22 \pm 0.02)$, and Rotthalmünster $(0.20 \pm 0.01)$ as indicated by small standard deviations. In Hohenheim $(0.27 \pm 0.06)$, the US100 dispersion reached a higher Range $\mathrm{fc}_{\mathrm{fc}}$ of $0.36 \pm 0.06$ compared to $\mathrm{H}_{2} \mathrm{O} 0.21 \pm 0.06$, Glassbeads $0.26 \pm 0.01$, and US450 $0.25 \pm 0.03$ (Figure 3). The site with the highest clay content Tänikon $(0.51 \pm 0.17)$ had the highest differentiation between the dispersion methods. $\mathrm{H}_{2} \mathrm{O}$ had a Range $\mathrm{f}_{\mathrm{fc} 4}$ of 0.42 \pm 0.05 , Glassbeads $0.28 \pm 0.06$ and the fractions of US100 and US450 reached a higher grade of isolation with $0.65 \pm 0.01$ and $0.70 \pm 0.02$, respectively. The average Range $\mathrm{f}_{\mathrm{fc}}$ of the methods was $0.25 \pm 0.09$ for $\mathrm{H}_{2} \mathrm{O}, 0.23 \pm 0.04$ for Glassbeads, $0.33 \pm$ 0.17 for US100 and $0.32 \pm 0.19$ for US450 (Figure 3). There were no significant differences in the Range $\mathrm{f}_{\mathrm{fc}}$ when comparing the mean Range $\mathrm{fc}_{\mathrm{fc}}$ of the methods without differentiating by the sites (Kruskal-Wallis rank-sum test). However, there are highly significant influences (ANOVA) on the Range $\mathrm{fc}_{\mathrm{f} 4}$ of the methods $(p<0.001)$ when adding the sites as grouping variable $(p<0.001)$ as well as the interaction of sites and methods $(p<0.001)$. A subsequent Tukey-HSD test identified the Range $_{\mathrm{fc} 4}$ of the sites as significantly different for three groups (Figure 3).

\section{Dispersion Effects on Organic Carbon, $\mathrm{C} / \mathrm{N}$ Ratio, and Mass Balance of Soil Fractions}

The OC contents tended to slightly decrease in the $>20 \mu \mathrm{m}$ fraction for all methods with increasing intensity of dispersion, while the contents within the $<20 \mu \mathrm{m}$ fraction increased by roughly equal amounts (Figure 4). The soils with low clay content tended to have higher OC contents in the fraction $<20 \mu \mathrm{m}$ than in the $>20 \mu \mathrm{m}$ fraction. Stronger dispersion led to changes in the mass balances of the fraction. The mass of the $>20 \mu \mathrm{m}$ fraction decreased with increasing dispersion intensity for all tested soils whilst the $<20 \mu \mathrm{m}$ fraction increased (Figure 5). The differences were more pronounced in the silty soils of Hohenheim and Rotthalmünster and the clayey soil of Tänikon than the sandy soils of Braunschweig and Jyndevad. This shift from the $>20 \mu \mathrm{m}$ fraction to the $<20 \mu \mathrm{m}$ fraction with increasing dispersion intensity was also measurable for SOC when comparing the OC mass contribution of the fractions between the tested dispersion methods (Supplementary Table 1, Supplementary Figure 2).

The mean $\mathrm{C} / \mathrm{N}$ ratio was higher in the $>20 \mu \mathrm{m}$ fraction $(17 \pm$ $0.3)$ than the $<20 \mu \mathrm{m}$ fraction $(10 \pm 0.1)$ (Figure 6). In the soil from Jyndevad, the $\mathrm{C} / \mathrm{N}$ ratio did not differ across the dispersion methods of each fraction. However, there were differences between the dispersion methods in the $>20 \mu \mathrm{m}$ fractions of the soils from Braunschweig, Rotthalmünster, Hohenheim, and Tänikon. While the $\mathrm{C} / \mathrm{N}$ ratio of the $>20 \mu \mathrm{m}$ fraction from these sites was 11-15 in samples treated with water or water and glass beads, it was higher using ultrasonication. The $\mathrm{C} / \mathrm{N}$ ratio ranged between 14 and 21 for the US100 method and 16-29 using the US450 method.

The mean mass loss was $<2 \%$ for all dispersion methods (Figure 7). With increasing intensity of the dispersion method, the mean mass loss increased slightly yet not significantly $(p>$ 0.05). The reproducibility of the $\mathrm{H}_{2} \mathrm{O}$ method was lower than the other methods indicated by a remarkably higher Range ${ }_{M}$ of $18.25 \mathrm{mg} \mathrm{g}^{-1}$ than the "Glassbeads" (7.38 $\left.\mathrm{mg} \mathrm{g}^{-1}\right)$, US100 (5.64 $\mathrm{mg} \mathrm{g}^{-1}$ ) and US450 (5.98 $\mathrm{mg} \mathrm{g}^{-1}$ ) methods (Figure 7). The mean OC loss ranged from $3.6 \pm 2.9 \%$ to $4.3 \pm 5.0 \%$, which is equivalent to $95.7 \%$ to $96.8 \% \mathrm{C}$ recovery, and was not significantly different between the methods $(p>0.05)$. The reproducibility of the $\mathrm{OC}$ content within the fractions marginally differed between the methods. The Range $_{C}$ between the replicates of each method was $0.94-1.35 \mathrm{mg} \mathrm{g}^{-1} \mathrm{C}$, and it was smaller than the mean Range $_{C}$ of repeated bulk soil measurements $(1.88 \mathrm{mg}$ $\left.\mathrm{g}^{-1} \mathrm{C}\right)$.

\section{Workload and Procedural Time}

For the dispersion methods, the working time ranged from $5 \mathrm{~min}$ for the $\mathrm{H}_{2} \mathrm{O}$ method to $15 \mathrm{~min}$ for the Glassbeads, US100 and US450 methods (Table 2). The total time until completing one sample was $15 \mathrm{~min}$ for US100, $30 \mathrm{~min}$ for US450, $30 \mathrm{~min}$ for $\mathrm{H}_{2} \mathrm{O}$, and $35 \mathrm{~min}$ using the glass beads. The duration of the sieving process depended on soil texture, taking 30-60 min total time when using the sieving machine and 30-75 min when sieving by hand. 


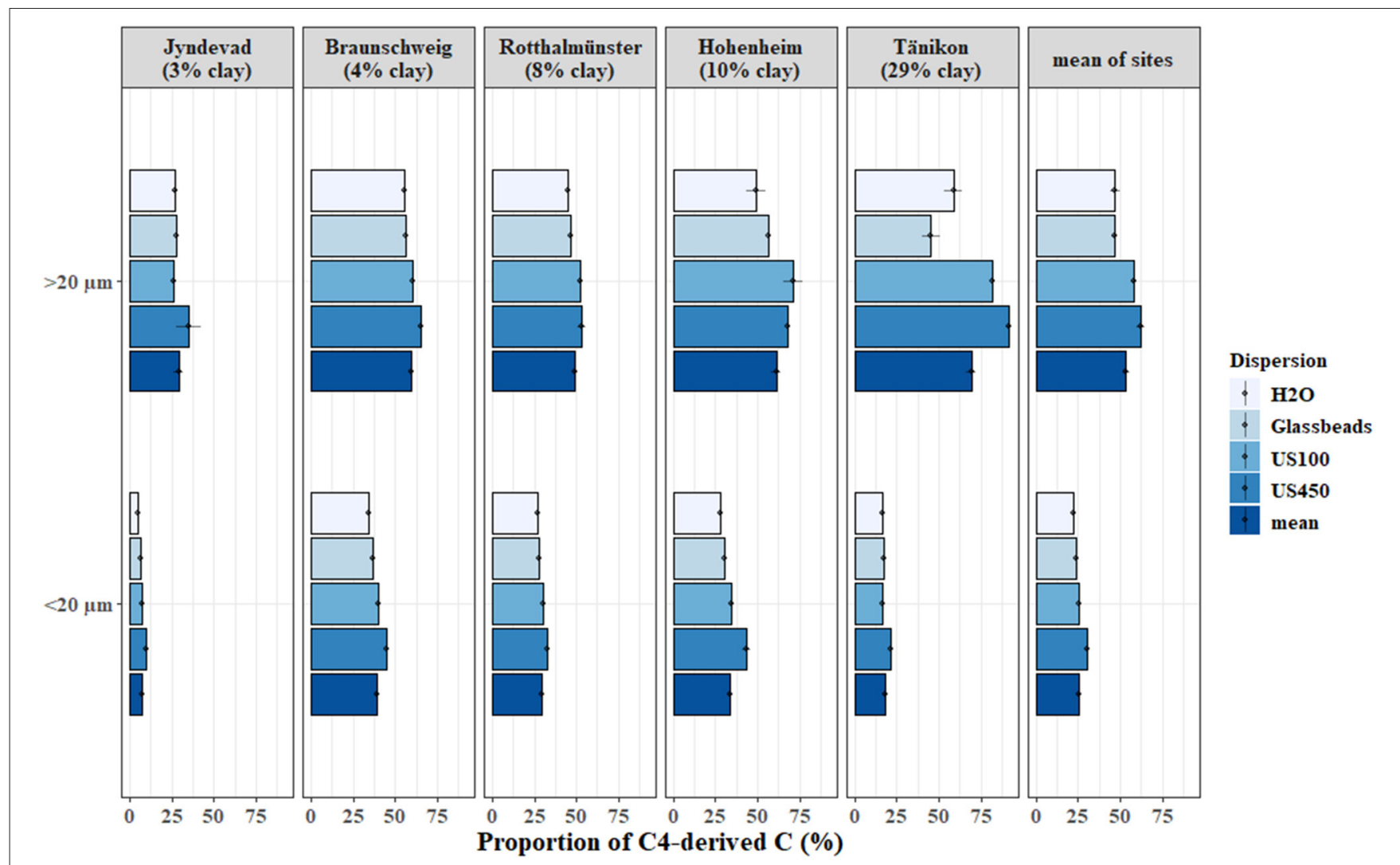

FIGURE 2 | Proportion of C4-derived C of the fractions $>20$ and $<20 \mu \mathrm{m}$ depicted for each dispersion method and site.

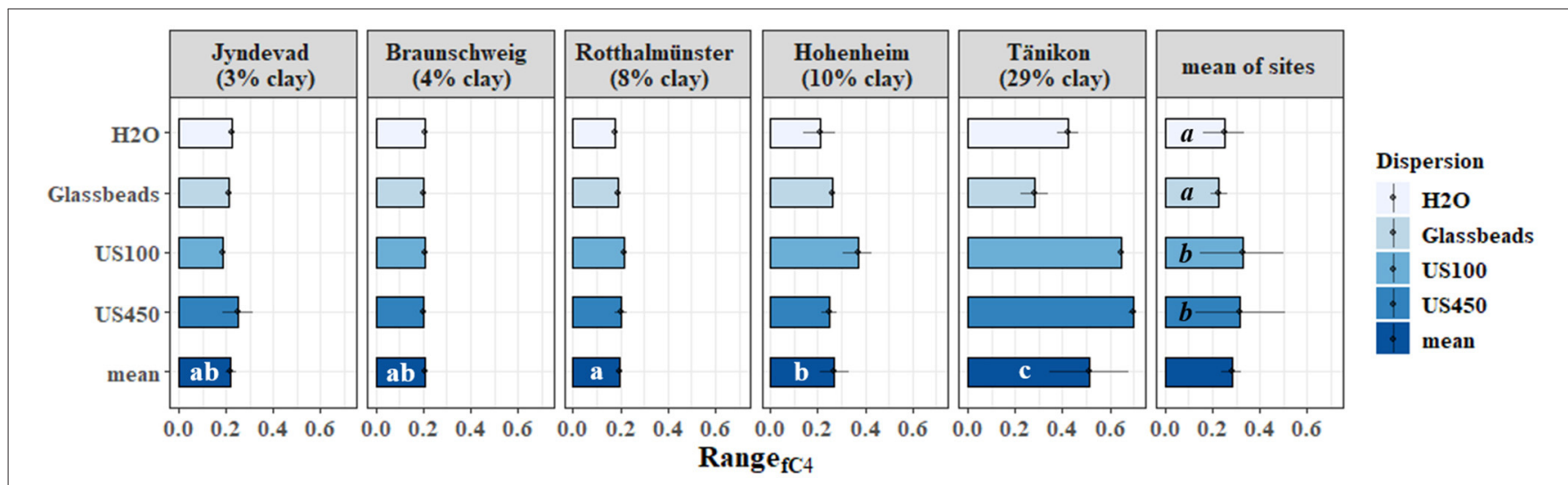

FIGURE 3 | Range fc4 $_{f}$ of the fractions $>20$ and $<20 \mu \mathrm{m}$ depicted for each dispersion method and site. Different letters indicate significant differences at $p<0.05$.

\section{Sodium Hexametaphosphate Subset Measurements}

Chemical dispersion using Na-HMP without rinsing includes the risk of damaging the equipment or increased costs due to the higher wear and tear of the hose system within the elemental analyzer, especially with the high sample throughput as intended. For this reason, we evaluated the Na-HMP dispersion with subsequent rinsing. Rinsing the samples down to an electrical conductivity (EC) of $<5 \mu \mathrm{S} \mathrm{cm} \mathrm{cm}^{-1}$ took at least 2 days and was therefore not suitable for a fast application. Additionally, we measured a significant SOC difference $(*$, Welch's $t$-test, $t=3.7373, d f=3.1485, p=$ 0.03074) in SOC contents between the rinsed samples and the control soils. The mean SOC contents were $79.8 \pm$ $1.5 \mathrm{mg} \mathrm{g}^{-1}$ in the control and $61.4 \pm 9.8 \mathrm{mg} \mathrm{g}^{-1}$ in the rinsed soils. 


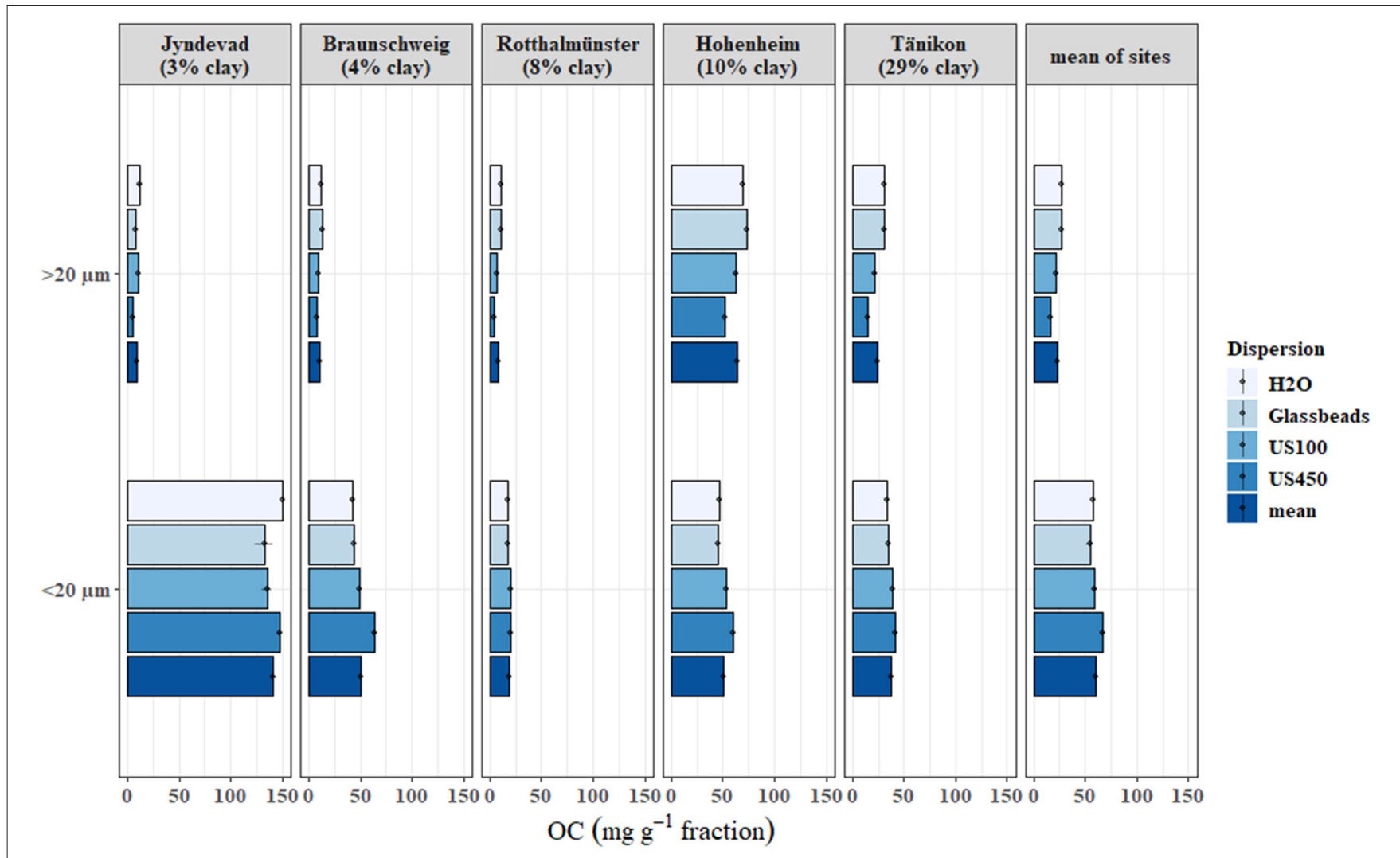

FIGURE 4 | Organic carbon (OC) content of the fractions >20 and $<20 \mu \mathrm{m}$ depicted for each dispersion method and site and their mean.

\section{DISCUSSION}

\section{Isolation Efficiencies of Dispersion Methods Are Related to Soil Texture}

All dispersion methods except the Na-HMP method revealed a high $\mathrm{C}$ recovery ranging from 95 to $97 \%$. A recent study that compared different fractionation methods (24) quantified the recovery of bulk SOC to an average of $95 \pm 4 \%$. Although it had the highest Range $\mathrm{M}_{\mathrm{M}}$ among the methods, the $\mathrm{H}_{2} \mathrm{O}$ method was the less reproducible than the other methods (Figure 7), which indicates that this method lacks the mechanic power to disperse the soil adequately. Our data indicated that the ultrasonication dispersions performed better when comparing the efficiency to isolate fractions with distinct turnover rates. However, these findings are only significant when taking the site, including the specific texture, vegetation, and age of the experiment, and the interaction of the site and dispersion method into account. The results showed that the site with the highest clay content of $29 \%$ (Tänikon) required a stronger dispersion with ultrasonication than the other sites to achieve fractions with better isolation of C3- and C4-derived organic carbon. Clay particles tend to form very stable microaggregates (52-54) and increase the proportion of macro-aggregates in the soil $(54,55)$. These macroaggregates obviously resisted weaker dispersion methods with $\mathrm{H}_{2} \mathrm{O}$ and glass beads $(19,31)$. Our results showed that the parameter for the isolation quality $\left(\right.$ Range $\left._{\mathrm{fc} 4}\right)$ is largely based on the increase of the moieties of $\mathrm{C} 4$-derived $\mathrm{C}$ and the $\mathrm{C} / \mathrm{N}$ ratio of the $>$ $20 \mu \mathrm{m}$ fraction (Figure 6, Supplementary Figure 3). In the $<$ $20 \mu \mathrm{m}$ fraction, the proportion of C4-derived $\mathrm{C}$ and the $\mathrm{C} / \mathrm{N}$ ratio were hardly changed with increasing dispersion intensity (Figure 6, Supplementary Figure 3). As the $<20 \mu \mathrm{m}$ fraction remained almost unchanged with the increasing intensity of dispersion, we conclude that the most important criterion for a successful isolation of fractions with different turnover is the degree of purity of C4-derived OC in the $>20 \mu \mathrm{m}$ fraction which is determined by the clay content of the respective soil (Supplementary Figure 4). The higher C/N ratio of the $>20 \mu \mathrm{m}$ fractions in the clayey soils with stronger dispersion is also explained by the destruction of microaggregates and the shift of MAOM into the $<20 \mu \mathrm{m}$ fraction. Moreover, differences in the OC content of the $>20 \mu \mathrm{m}$ fraction when using $\mathrm{H}_{2} \mathrm{O}$ and US450 might also be used to calculate the amount of C in the "occluded/aggregate protected" POM fraction (o-POM), obtaining data similar to that from density fractionation methods $(14,56)$, but avoiding their high cost. Such an approach would need to be tested to check the uncertainty of the results obtained from calculation compared to density fractionation.

\section{Comparison of Isolation Qualities}

We used the Range $\mathrm{f}_{\mathrm{fc}}$ indicator to compare the isolation quality of the investigated dispersion methods with methods investigated in a former study (24) that used soils of mostly the same 


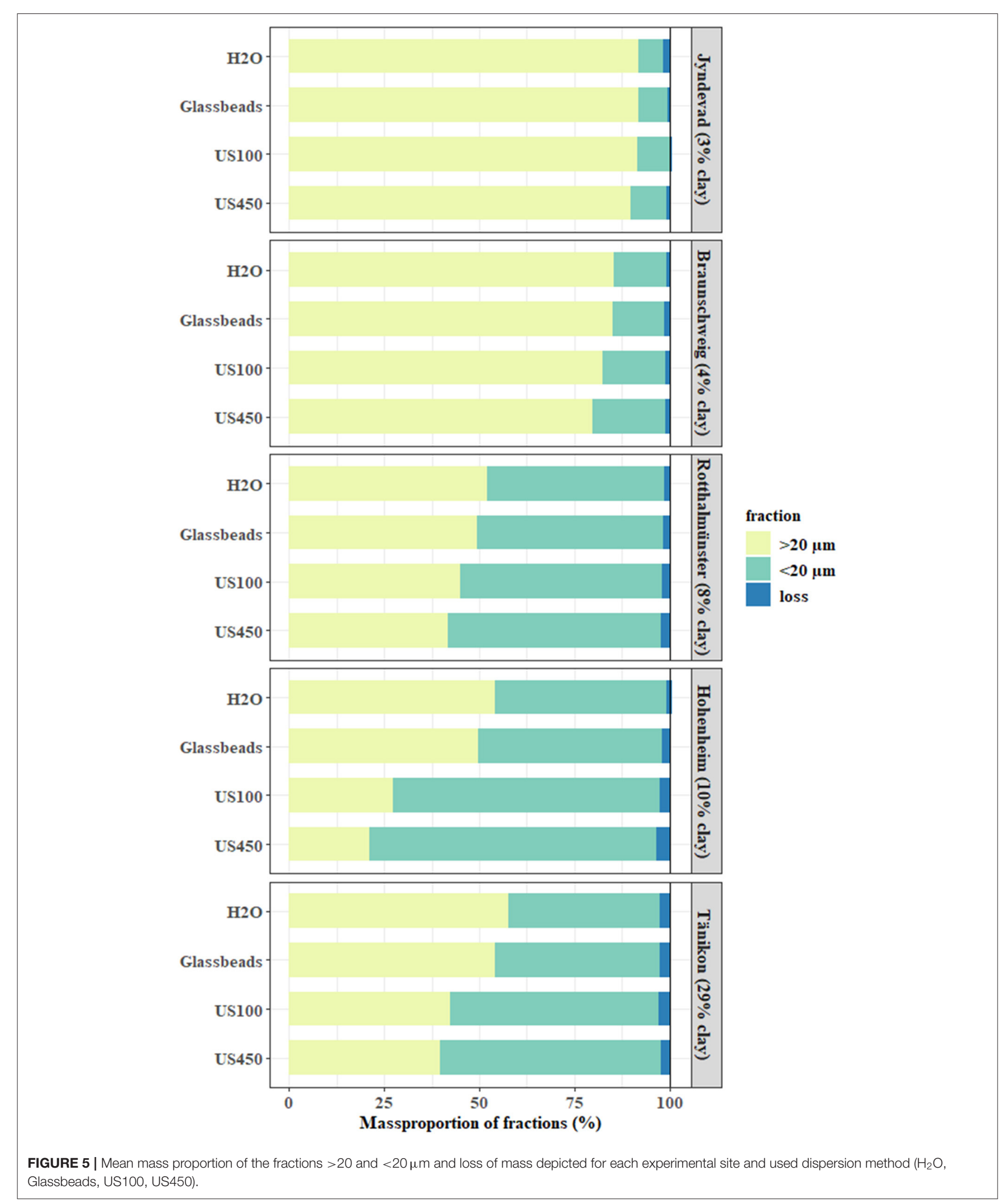




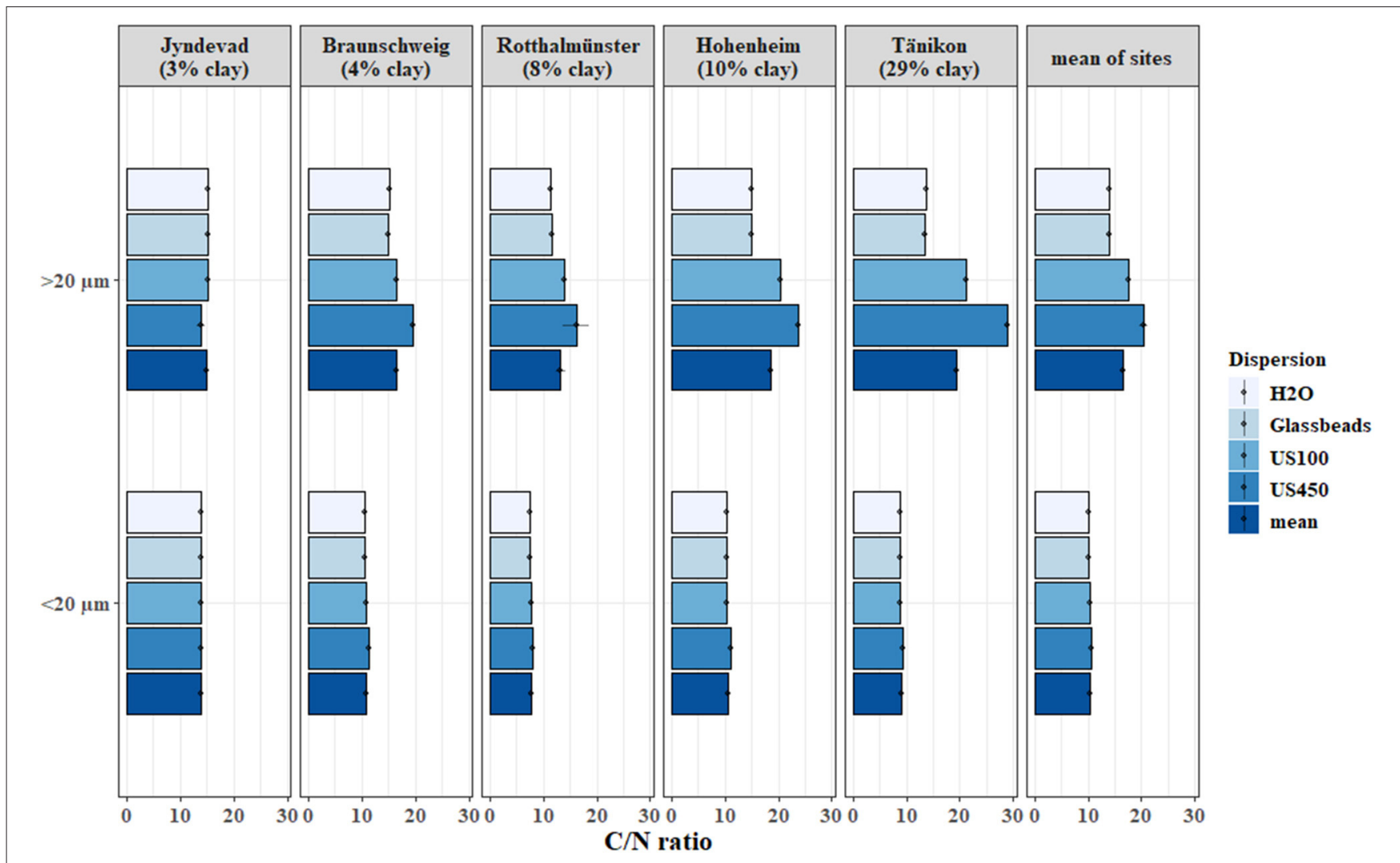

FIGURE 6 | C/N ratio of the fractions $>20$ and $<20 \mu \mathrm{m}$ depicted for each dispersion method and site and their mean.

long-term experiments. One of the tested fractionation methods within that study (40) combined the use of ultrasonication and glass beads but separated soils into four fractions $(2,000-$ $200,200-50,50-20$, and $<20 \mu \mathrm{m}$ ) and was thus methodically comparable to our approach. Despite being more elaborate, this method had no isolation advantage with a mean Range $\mathrm{fc}_{\mathrm{fc}}$ indicator of 0.22 compared to $0.23-0.33$ in our methods. Other methods evaluated in this study that had evidently higher Range $\mathrm{fc}_{\mathrm{fc}}[(17,19,57-59)$; in Poeplau et al. (24)] all used chemical agents either for density fractionation (sodium polytungstate), alkaline extraction (sodium diphosphate) or OM oxidation $\left(\mathrm{H}_{2} \mathrm{O}_{2}, \mathrm{NaOCl}_{2}\right)$. Besides higher work load through acquisition of additional fractions that have to be investigated and measured separately, chemical agents might change the chemical composition of POM $(60,61)$. However, water has no effect on the chemistry of POM (60). Additionally, to our knowledge, there is no evidence of ultrasonication altering the chemistry of POM.

\section{Limited Performance of Chemical Dispersion With Sodium-Hexametaphosphate}

Although Na-HMP is widely used for soil dispersion $(16,46$, 62 ), our attempts to use it within a simplified fractionation scheme were not successful. Na-HMP needs to be rinsed out or maintained within the samples. It has a melting point of $628^{\circ} \mathrm{C}$, and in the presence of moisture it is hydrolyzed to Na-trimetaphosphate with a melting point of $53^{\circ} \mathrm{C}$. During combustion in an elemental analyzer or IRMS, it will dissolve and precipitate within devices, and it may damage equipment, especially when the number of measurements is high. Therefore, most laboratories filtrate the soil and rinse the salt with deionized water. Rinsing the Na-HMP increasing the work load, depending on soil texture and OC content. A sample required an average time of 2-8 days to be rinsed before reaching an EC $<5 \mu \mathrm{S}$ $\mathrm{cm}^{-1}$. Rinsing resulted in significant SOC extraction and thus SOC loss. This concurs with another study revealing critical changes in soils due to the use of sodium salts and rinsing (63). Therefore, we cannot recommend using Na-HMP as a fast and simple dispersion method. Furthermore, our results imply that the $\mathrm{OC}$ recovery rate is indispensable to evaluate the outcome of OC fractionation methods.

\section{Evaluation of Performance Indicators and Time Expenditure}

Our results showed that all dispersion methods have trade-offs in either isolation qualities, equipment and workload requirements or recovery and reproducibility criteria. In terms of the workload, Poeplau et al. (24) emphasized the correlation of increasing workloads with higher numbers of fractions. Additionally, the use of chemical agents significantly extends the fractionation 

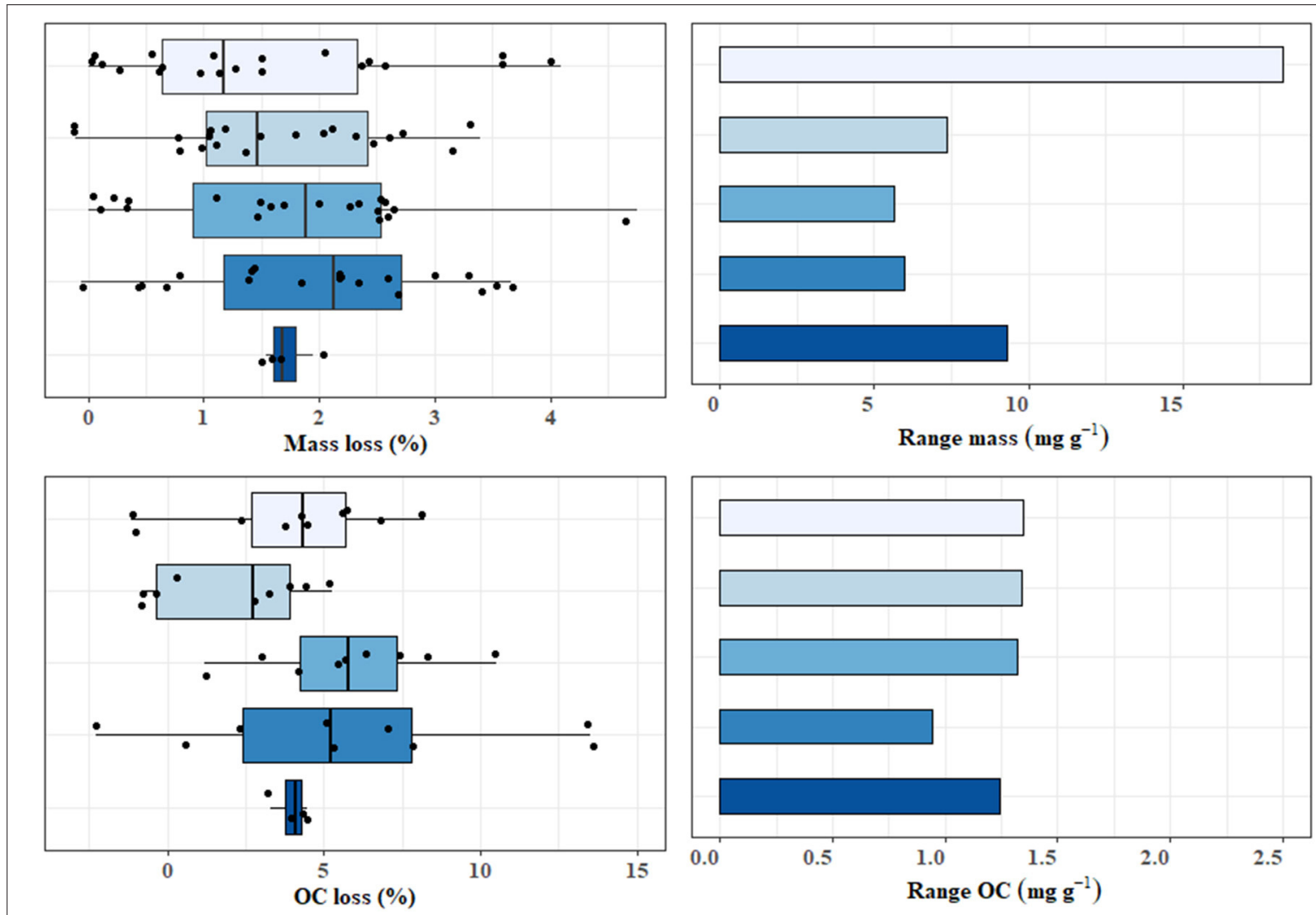

method
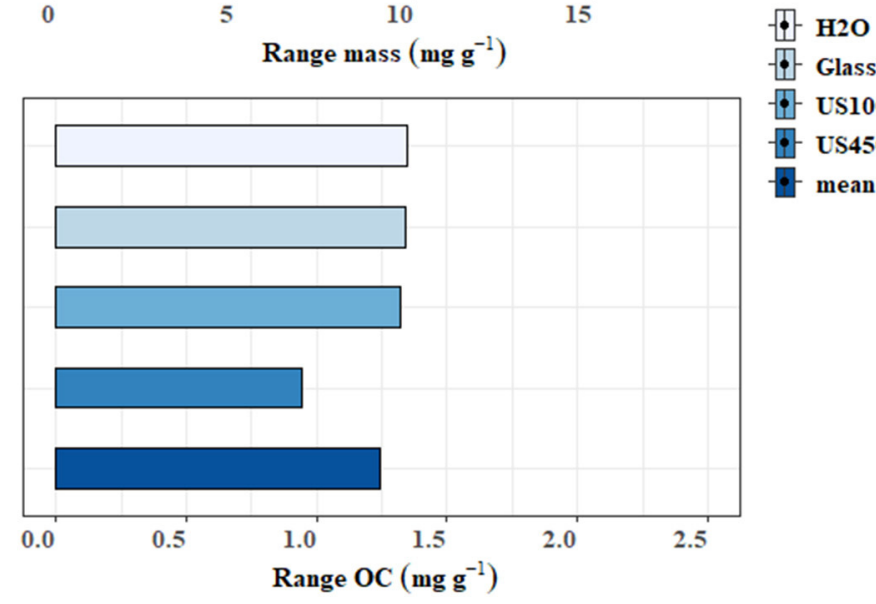

Glassbeads

FIGURE 7 | Mass loss (left top) and C loss (left bottom) shown as indicators for mass and C recovery and Range mass/Range OC shown as indicators for mass/C reproducibility for the used dispersions and the mean of all dispersions $\left(\mathrm{H}_{2} \mathrm{O}\right.$, Glassbeads, US100, US450, mean). Low mass/C loss report high recovery whereas low Range $\mathrm{C} /$ mass report high reproducibility.

TABLE 2 | Mean values of the quality indicators mass loss (recovery)/reproducibility, C loss (recovery)/reproducibility, Range $f_{C 4}$ and active, and total work time for each dispersion method.

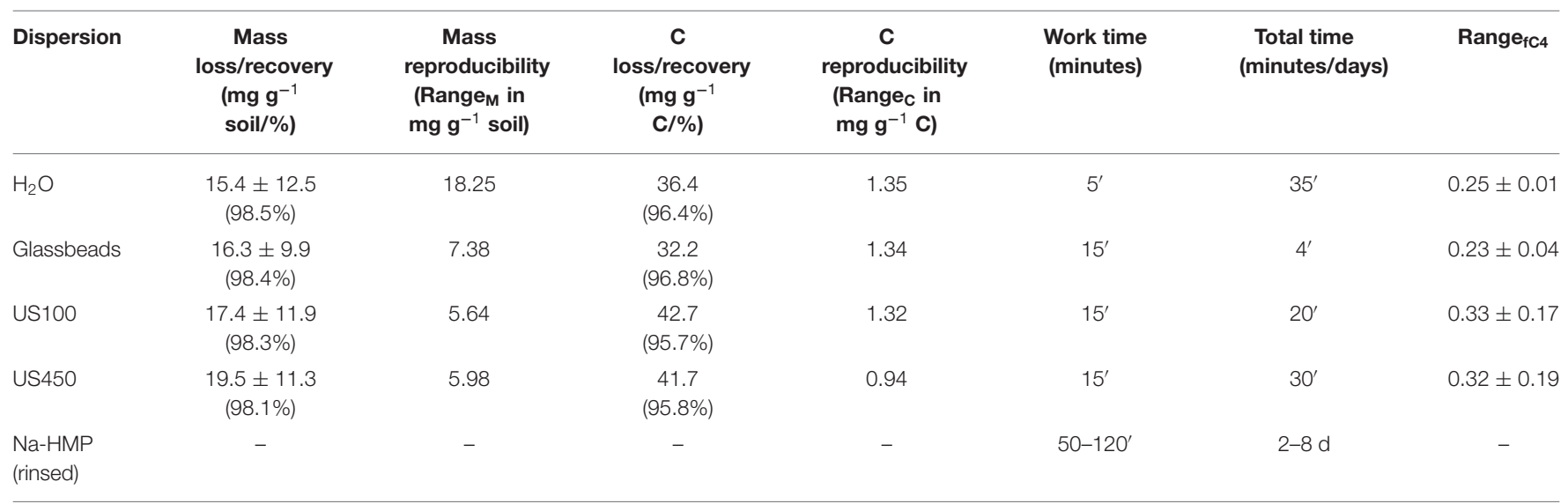

process, as long as these chemicals are removed from the fractions afterwards. All dispersion methods tested, except the Na-HMP treatment, had a relatively short working time. The total time requirements of the methods was slightly shorter for ultrasonication than the $\mathrm{H}_{2} \mathrm{O}$ and glassbeads methods (Table 3). Costs depend on the workload and equipment used and can be divided into running costs and fixed costs. Ultrasonication devices have relatively high fixed costs and the sonotrodes need to be changed regularly, causing relatively higher running costs than other methods. Because costs are strongly related to market volatility and country-specific wage costs, we do not evaluate these costs in detail. Another vital factor regarding time expenditure is the amount of water used during wet sieving. Depending on soil texture, we used 3-101 of deionized water, 
TABLE 3 | Evaluation of quality and efficiency criteria describing the performance of each work step of the modules dispersion, wet sieving, and drying.

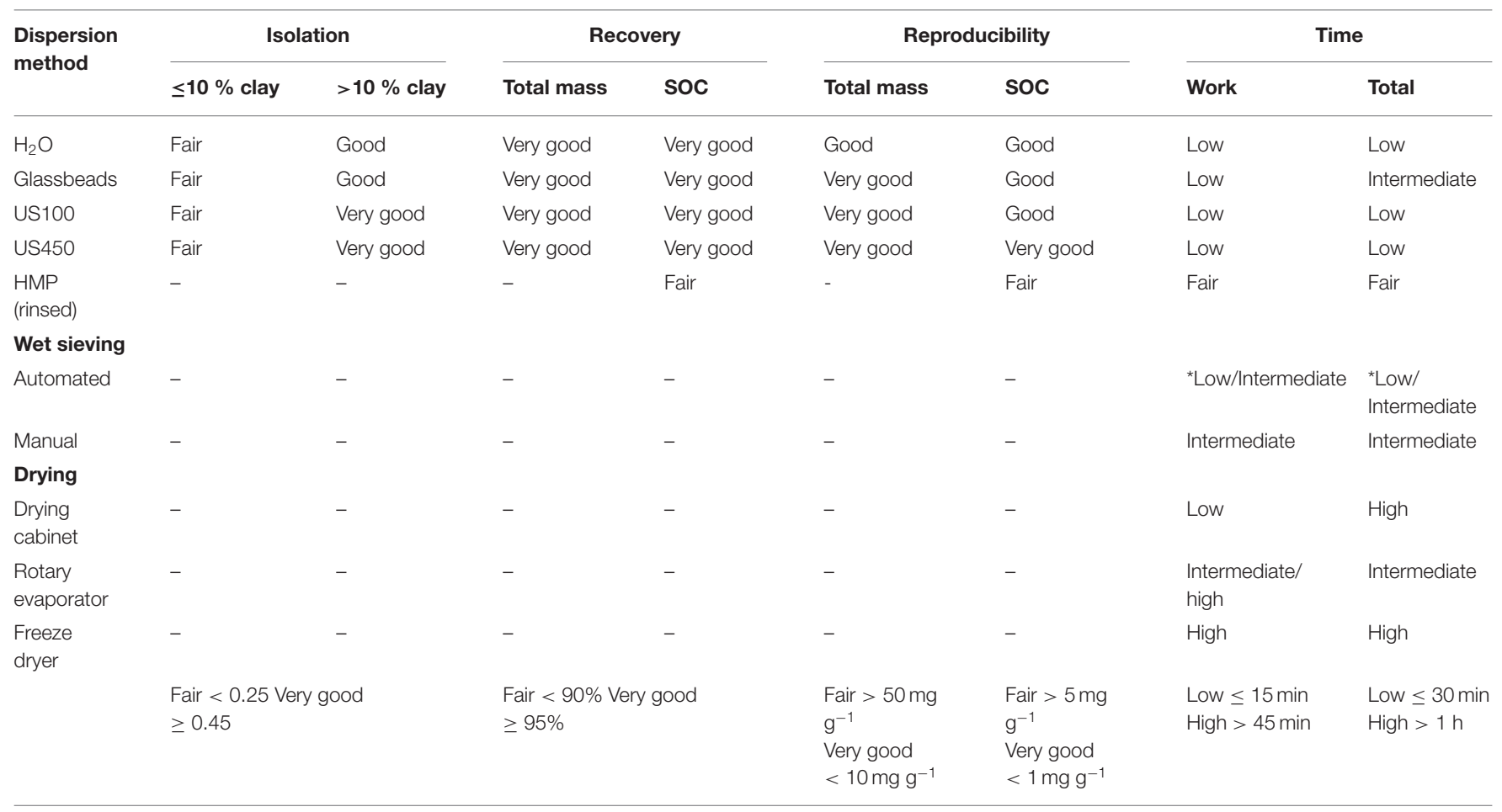

${ }^{*}$ Dependent to soil texture.

as we wanted to achieve the best possible separation indicated by rinsed water without any remaining colloids after sieving. However, other studies suggest using the lowest amount of deionized water possible to prevent DOM leaching (48) and recommend the use of 21 of deionized water. We assume that both effects, either the leaching of DOM, or the insufficient translocation of $<20 \mu \mathrm{m}$ particles after the use of only $2,000 \mathrm{ml}$ of deionized water, will most likely not affect the OC balance significantly. Automated sieving is slightly faster than manual sieving. However, this effect diminishes with increasing difference in the mean particle size of the soil to the mesh size and recovery and reproducibility might differ between both methods. In terms of the time expenditures of the drying methods, drying cabinets are advantageous, but the drying process itself takes several days depending on the volume of water requiring evaporation and the power of the device. Big rotary evaporators working at low pressure are capable of evaporating large volumes of water, such as $10 \mathrm{l}$ within $4 \mathrm{~h}$ in our case, but they also come with a higher workload due to the cumbersome cleaning of the vessels. Freeze dryers require both intermediate to high workloads and long drying times, but they have the advantage that they simplify the recovery from vessels. Therefore, they are beneficial when working with small amounts of soil. A complete scheme and timeframe of the experiment and the fractionation steps can be seen in Supplementary Figure 1.

\section{Limitations}

This study focused on agricultural soils in Central Europe. Although the methods might be usable on soils under different conditions, they were calibrated to isolate and quantify POM and MAOM content/stocks under criteria specific to Central Europe. Therefore, we cannot recommend them for use on soils with divergent land management or origin without former method calibration and optimization. Additionally, their efficiencies could be different for soils with a clay mineral composition different to that of central European soils, carbonaceous soils, organic soils, or OM-rich soils such as forest soils or soils with special conditions related to organic or inorganic carbon. Moreover, we did not compare different mesh sizes within the sieving process, such as 50 and $63 \mu \mathrm{m}$. Furthermore, we want to emphasize that the number of replicates $(n=2)$ used in this study is low, especially with regard to the reproducibility indicator, which is causing uncertainty. Nevertheless, we consider the number of replicates as adequate for the precision of the approach indicated by high reproducibility, low variance and high $2{ }^{13} \mathrm{C}$-recovery as outlined in Figures 2, 7 and Supplementary Table 2.

\section{CONCLUSIONS}

Our study showed that a simple soil fractionation into two particle size fractions of $>20$ and $<20 \mu \mathrm{m}$ is a functional tool to assess information on SOC fractions with different turnover rates. However, the differentiation in SOC pools with distinct turnover rates strongly depends on soil texture and the dispersion method used. Clay-rich soils required higher dispersion intensities whereas soils with lower clay 
contents showed no differences in their dispersion methods. Ultrasonication with $450 \mathrm{~J} \mathrm{ml}^{-1}$ has the overall best quality indicators in isolation of two fractions with different turnover time and in reproducibility compared to dispersion methods using water with or without glass beads and is therefore best suited for a simple fractionation. It enables a relatively quick and inexpensive, but nevertheless precise, assessment of functional SOM pools, which enables the estimation of management influences on soil functions such as nutrient turnover $(\mathrm{POM})$ or $\mathrm{C}$ sequestration $(\mathrm{MAOM})$. Due to the substantial potential of simple fractionation to estimate influences of cultivation or land use on associated soil functions, application in agriculture is promising, especially on a larger spatial (regional, national) scale with a large sample size. In particular, the method could be implemented within existing soil monitoring programs. Additionally, there is the option of using fractionation of archived soil samples to trace the development of the fast and slow cycling $\mathrm{C}$ pools of soils up to the present day.

\section{DATA AVAILABILITY STATEMENT}

The raw data supporting the conclusions of this article will be made available by the authors, without undue reservation.

\section{REFERENCES}

1. Lal R. Soil health and carbon management. Food Energy Secur. (2016) 5:212222. doi: $10.1002 /$ fes3.96

2. Paustian $\mathrm{K}$, Andrén $\mathrm{O}$, Janzen $\mathrm{HH}$, Lal R, Smith P, Tian G, et al. Agricultural soils as a sink. Soil Use Manag. (1997) 13:230-44. doi: 10.1111/j.1475-2743.1997.tb00594.x

3. Wiesmeier M, Urbanski L, Hobley E, Lang B, von Lützow M, MarinSpiotta E, et al. Soil organic carbon storage as a key function of soils - a review of drivers and indicators at various scales. Geoderma. (2019) 333:14962. doi: 10.1016/j.geoderma.2018.07.026

4. Ciais P, Sabine C, Bala G, Bopp L, Brovkin V, Canadell J, et al. Carbon and Other Biogeochemical Cycles. In: Stocker TF, Qin D, Plattner G-K, Tignor M, Allen SK, Boschung J, et al. Climate Change 2013: The Physical Science Basis. Contribution of Working Group I to the Fifth Assessment Report of the Intergovernmental Panel on Climate Change (New York, NY: Cambridge University Press).

5. Jarecki MK, Lal R. Crop management for soil carbon sequestration. Crit Rev Plant Sci. (2003) 22:471-502. doi: 10.1080/713608318

6. Vogel HJ, Eberhardt E, Franko U, Lang B, Lie ßM, Weller U, et al. Quantitative evaluation of soil functions: potential and state. Front Environ Sci. (2019) 7:164. doi: 10.3389/fenvs.2019.00164

7. Oades JM. The retention of organic matter in soils. Biogeochemistry. (1988) 5:35-70. doi: 10.1007/BF02180317

8. Moni C, Derrien D, Hatton PJ, Zeller B, Kleber M. Density fractions versus size separates: does physical fractionation isolate functional soil compartments? Biogeosciences Discuss. (2012) 9:8405-47. doi: 10.5194/bgd-9-8405-2012

9. Chenu C, Rumpel C, Lehmann J. Methods for Studying Soil Organic Matter. 4th ed. Waltham: Elsevier Inc (2015). doi: 10.1016/B978-0-12-415955-6.00013-X

10. Six J, Elliott ET, Paustian K. Aggregate and soil organic matter dynamics under conventional and No-tillage systems. Soil Sci Soc Am J. (1999) 63:13501358. doi: 10.2136/sssaj1999.6351350x

11. Helfrich M, Ludwig B, Buurman P, Flessa H. Effect of land use on the composition of soil organic matter in density and aggregate fractions as

\section{AUTHOR CONTRIBUTIONS}

CJ conducted the experiments and prepared the first manuscript draft. CJ and MW analyzed the data. All authors conceived the experiment and contributed to its refinement.

\section{FUNDING}

This project work was funded by the German Federal Ministry of Education and Research (BMBF) in the framework of the funding measure Soil as a Sustainable Resource for the BioeconomyBonaRes, project BonaRes (Module B): BonaRes Center for Soil Research, subproject C (Grant No. 031B0511C).

\section{ACKNOWLEDGMENTS}

We are grateful to Anette Goeske and the staff of the Stable Isotope Laboratory of Thünen Institute for IRMS measurements and valuable advice.

\section{SUPPLEMENTARY MATERIAL}

The Supplementary Material for this article can be found online at: https://www.frontiersin.org/articles/10.3389/fsoil. 2021.692583/full\#supplementary-material

revealed by solid-state 13C NMR spectroscopy. Geoderma. (2006) 136:33141. doi: 10.1016/j.geoderma.2006.03.048

12. Kravchenko AN, Wang ANW, Smucker AJM, Rivers ML. Long-term differences in tillage and land use affect intra-aggregate pore heterogeneity. Soil Sci Soc Am J. (2011) 75:1658-66. doi: 10.2136/sssaj2011.0096

13. von Lützow M, Kögel-Knabner I, Ekschmitt K, Flessa H, Guggenberger G, Matzner E, et al. SOM fractionation methods: Relevance to functional pools and to stabilization mechanisms. Soil Biol Biochem. (2007) 39:2183207. doi: 10.1016/j.soilbio.2007.03.007

14. Cambardella CA, Elliot ET. Particulate soil organic-matter changes across a grassland cultivation sequence. Soil Sci Sock Am J. (1992) 56:77783. doi: 10.2136/sssaj1992.03615995005600030017x

15. Christensen BT. Physical fractionation of soil and organic matter in primary particle size and density separates. Adv Soil Sci. (1992) 20:190. doi: 10.1007/978-1-4612-2930-8_1

16. Six J, Elliott ET, Paustian K, Doran JW. Aggregation and soil organic matter accumulation in cultivated and native grassland soils. Soil Sci Soc Am J. (1998) 62:1367-77. doi: 10.2136/sssaj1998.03615995006200050032x

17. Zimmermann M, Leifeld J, Schmidt MWI, Smith P, Fuhrer J. Measured soil organic matter fractions can be related to pools in the RothC model. Eur J Soil Sci. (2007) 58:658-67. doi: 10.1111/j.1365-2389.2006.00855.x

18. Steffens M, Kölbl A, Kögel-Knabner I. Alteration of soil organic matter pools and aggregation in semi-arid steppe topsoils as driven by organic matter input. Eur J Soil Sci. (2009) 60:198-212. doi: 10.1111/j.1365-2389.2008.01104.x

19. Balesdent J. The turnover of soil organic fractions estimated by radiocarbon dating. Sci Total Environ. (1987) 62:4058. doi: 10.1016/0048-9697(87)90528-6

20. Balesdent $J$. The significance of organic separates to carbon dynamics and its modelling in some cultivated soils. Eur J Soil Sci. (1996) 47:48593. doi: 10.1111/j.1365-2389.1996.tb01848.x

21. Hassink J. A model of the physical protection of organic matter in soils the capacity of soils to preserve organic $\mathrm{C}$ and $\mathrm{N}$ by their association with clay and silt particles. Plant Soil. (1997) 191:77-87. doi: 10.1023/A:1004213929699

22. Amelung W, Bol R, Friedrich C. Natural 13C abundance: A tool to trace the incorporation of dung-derived carbon into soil 
particle-size fractions. Rapid Commun Mass Spectrom. (1999) 13:12914. doi: 10.1002/(SICI)1097-0231(19990715)13:13<1291::AID-RCM637>3.0. $\mathrm{CO} ; 2-\mathrm{C}$

23. Rumpel C, Kögel-Knabner I, Knicker H, Hüttl RF. Composition and distribution of organic matter in physical fractions of a rehabilitated mine soil rich in lignite-derived carbon. Geoderma. (2000) 98:17792. doi: 10.1016/S0016-7061(00)00060-4

24. Poeplau C, Don A, Six J, Kaiser M, Benbi D, Chenu C, et al. Isolating organic carbon fractions with varying turnover rates in temperate agricultural soils - a comprehensive method comparison. Soil Biol Biochem. (2018) 125:1026. doi: 10.1016/j.soilbio.2018.06.025

25. Christensen BT. Matching measurable soil organic matter fractions with conceptual pools in simulation models of carbon turnover: revision of model structure. Eval Soil Org Matter Model. (1996) 38:143-159. doi: 10.1007/978-3-642-61094-3_11

26. Cotrufo MF, Ranalli MG, Haddix ML, Six J, Lugato E. Soil carbon storage informed by particulate and mineral-associated organic matter. Nat Geosci. (2019) 12:989-94. doi: 10.1038/s41561-019-0484-6

27. Lavallee JM, Soong JL, Cotrufo MF. Conceptualizing soil organic matter into particulate and mineral-associated forms to address global change in the 21st century. Glob Chang Biol. (2019) 26:261-273. doi: 10.1111/gcb. 14859

28. von Lützow M, Kögel-Knabner I, Ludwig B, Matzner E, Flessa H, Ekschmitt K, et al. Stabilization mechanisms of organic matter in four temperate soils: development and application of a conceptual model. J Plant Nutr Soil Sci. (2008) 171:111-24. doi: 10.1002/jpln.2007 00047

29. Parton WJ, Stewart JWB, Cole CV. Dynamics of C. N, P and S in grassland soils: a model. Biogeochemistry. (1988) 5:109-31. doi: 10.1007/BF02180320

30. Bonde TA, Christensen BT, Cerri CC. Dynamics of soil organic matter as reflected by natural $13 \mathrm{C}$ abundance in particle size fractions of forested and cultivated oxisols. Soil Biol Biochem. (1992) 24:275-7. doi: 10.1016/0038-0717(92)90230-U

31. van Wesemael B, Chartin C, Wiesmeier M, von Lützow M, Hobley E, Carnol $\mathrm{M}$, et al. An indicator for organic matter dynamics in temperate agricultural soils. Agric Ecosyst Environ. (2019) 274:62-75. doi: 10.1016/j.agee.2019.01.005

32. Six J, Conant RT, Paul EA, Paustian K. 2002 six stabilizatio nmechanisms of SOM implications for C saturation of soils.pdf. Plant Soil. (2002) 241:15576. doi: 10.1023/A:1016125726789

33. Stewart CE, Paustian K, Conant RT, Plante AF, Six J. Soil carbon saturation: concept, evidence and evaluation. Biogeochemistry. (2007) 86:1931. doi: 10.1007/s10533-007-9140-0

34. Castellano MJ, Mueller KE, Olk DC, Sawyer JE, Six J. Integrating plant litter quality, soil organic matter stabilization, and the carbon saturation concept. Glob Chang Biol. (2015) 21:3200-9. doi: 10.1111/gcb.12982

35. Coleman K, Jenkinson DS. RothC-26.3 - a model for the turnover of carbon in soil. Eval Soil Org Matter Model. (1996) 38:237-46. doi: 10.1007/978-3-642-61094-3_17

36. Chen S, Arrouays D, Angers DA, Chenu C, Barré P, Martin MP, et al. National estimation of soil organic carbon storage potential for arable soils: a datadriven approach coupled with carbon-landscape zones. Sci Total Environ. (2019) 666:355-67. doi: 10.1016/j.scitotenv.2019.02.249

37. Dechow R, Franko U, Kätterer T, Kolbe H. Evaluation of the RothC model as a prognostic tool for the prediction of SOC trends in response to management practices on arable land. Geoderma. (2019) 337:46378. doi: 10.1016/j.geoderma.2018.10.001

38. Chenu C, Plante AT. Clay-sized organo-mineral complexes in a cultivation chronosequence: revisiting the concept of the "primary organo-mineral complex." Eur J Soil Sci. (2006) 57:596-607. doi: 10.1111/j.1365-2389.2006.00834.x

39. Plante AF, Conant RT, Stewart CE, Paustian K, Six J. Impact of soil texture on the distribution of soil organic matter in physical and chemical fractions. Soil Sci Soc Am J. (2006) 70:287-96. doi: 10.2136/sssaj2004.0363

40. Rovira $\mathrm{P}$, Jorba $\mathrm{M}$, Romanyà $\mathrm{J}$. Active and passive organic matter fractions in mediterranean forest soils. Biol Fertil Soils. (2010) 46:35569. doi: 10.1007/s00374-009-0437-0

41. Tiessen H, Stewart JWB. Particle-size fractions and their use in studies of soil organic matter: II. Cultivation effects on organic matter composition in size fractions. Soil Sci Soc Am J. (1983) 47:509-14. doi: 10.2136/sssaj1983.036159950047000 $30023 \mathrm{x}$

42. Kölbl A, Leifeld J, Kögel-Knabner I. A comparison of two methods for the isolation of free and occluded participate organic matter. J Plant Nutr Soil Sci. (2005) 168:660-7. doi: 10.1002/jpln.200521805

43. Kaiser M, Berhe AA, Sommer M, Kleber M. Application of ultrasound to disperse soil aggregates of high mechanical stability. J Plant Nutr Soil Sci. (2012) 175:521-6. doi: 10.1002/jpln.201200077

44. Tyner EH. The use of sodium metaphosphate for dispersion of soils for mechanical analysis. Soil Sci Soc Am J. (1940) 4:106-13. doi: 10.2136/sssaj1940.036159950004000C0020x

45. Six J, Merckx R, Kimpe K, Paustian K, Elliott ET. A re-evaluation of the enriched labile soil organic matter fraction. Eur J Soil Sci. (2000) 51:28393. doi: 10.1046/j.1365-2389.2000.00304.x

46. Sanderman J, Fillery IRP, Jongepier R, Massalsky A, Roper MM, MacDonald LM, et al. Carbon sequestration under subtropical perennial pastures II: carbon dynamics. Soil Res. (2013) 51:771-80. doi: 10.1071/SR12351

47. Graf-Rosenfellner M, Kayser G, Guggenberger G, Kaiser K, Büks F, Kaiser M, et al. Replicability of aggregate disruption by sonication-an inter-laboratory test using three different soils from Germany. J Plant Nutr Soil Sci. (2018) 181:894-904. doi: 10.1002/jpln.201800152

48. Poeplau C, Don A. Sensitivity of soil organic carbon stocks and fractions to different land-use changes across Europe. Geoderma. (2013) 192:189201. doi: 10.1016/j.geoderma.2012.08.003

49. Schmidt MWI, Rumpel C, Kögel-Knabner I. Evaluation of an ultrasonic dispersion procedure to isolate primary organomineral complexes from soils. Eur J Soil Sci. (1999) 50:87-94. doi: 10.1046/j.1365-2389.1999.00211.x

50. Menichetti L, Ekblad A, Kätterer T. Organic amendments affect $\delta 13 \mathrm{C}$ signature of soil respiration and soil organic $\mathrm{C}$ accumulation in a long-term field experiment in Sweden. Eur J Soil Sci. (2013) 64:6218. doi: $10.1111 /$ ejss. 12077

51. Hothorn T, Bretz F, Westfall P. Simultaneous inference in general parametric models. Biometrical J. (2008) 50:346-63. doi: 10.1002/bimj.200810425

52. Wagner S, Cattle SR, Scholten T. Soil-aggregate formation as influenced by clay content and organic-matter amendment. J Plant Nutr Soil Sci. (2007) 170:173-80. doi: 10.1002/jpln.200521732

53. Kaiser K, Kalbitz K. Cycling downwards - dissolved organic matter in soils. Soil Biol Biochem. (2012) 52:29-32. doi: 10.1016/j.soilbio.2012.04.002

54. Krause L, Rodionov A, Schweizer SA, Siebers N, Lehndorff E, Klumpp E, et al. Microaggregate stability and storage of organic carbon is affected by clay content in arable Luvisols. Soil Tillage Res. (2018) 182:1239. doi: 10.1016/j.still.2018.05.003

55. Schweizer SA, Bucka FB, Graf-Rosenfellner M, Kögel-Knabner I. Soil microaggregate size composition and organic matter distribution as affected by clay content. Geoderma. (2019) 355:113901. doi: 10.1016/j.geoderma.2019.113901

56. Christensen BT. Physical fractionation of soil and structural and functional complexity in organic matter turnover. Eur J Soil Sci. (2001) 52:34553. doi: 10.1046/j.1365-2389.2001.00417.x

57. Leifeld J, Kögel-Knabner I. Organic carbon and nitrogen in fine soil fractions after treatment with hydrogen peroxide. Soil Biol Biochem. (2001) 33:21558. doi: 10.1016/S0038-0717(01)00127-4

58. Sollins P, Kramer MG, Swanston C, Lajtha K, Filley T, Aufdenkampe $\mathrm{AK}$, et al. Sequential density fractionation across soils of contrasting mineralogy: evidence for both microbial- and mineralcontrolled soil organic matter stabilization. Biogeochemistry. (2009) 96:209-31. doi: 10.1007/s10533-009-9359-z

59. Kaiser M, Zederer DP, Ellerbrock RH, Sommer M, Ludwig B. Effects of mineral characteristics on content, composition, and stability of organic matter fractions separated from seven forest topsoils of different pedogenesis. Geoderma. (2016) 263:1-7. doi: 10.1016/j.geoderma.2015.08.029

60. Chen $\mathrm{X}$, Jin $\mathrm{M}, \mathrm{Xu} \mathrm{Y}$, Chu $\mathrm{W}$, Olk DC, Hu J, et al. Potential alterations in the chemical structure of soil organic matter components during sodium hydroxide extraction. J Environ. Qual. (2019) 48:157886. doi: $10.2134 /$ jeq2019.02.0077

61. Ohno T, Hess NJ, Qafoku NP. Current understanding of the use of alkaline extractions of soils to investigate soil organic matter and environmental 
processes. J Environ Qual. (2019) 48:1561-4. doi: 10.2134/jeq2019. 08.0292

62. Robertson AD, Paustian K, Ogle S, Wallenstein MD, Lugato E, Cotrufo MF. Unifying soil organic matter formation and persistence frameworks: the MEMS model. Biogeosci Discuss. (2018) 16:1-36. doi: 10.5194/bg-20 $18-430$

63. Plaza C, Giannetta B, Benavente I, Vischetti C, Zaccone C. Density-based fractionation of soil organic matter: effects of heavy liquid and heavy fraction washing. Sci Rep. (2019) 9:10146. doi: 10.1038/s41598-019-46577-y

Conflict of Interest: The authors declare that the research was conducted in the absence of any commercial or financial relationships that could be construed as a potential conflict of interest.
Publisher's Note: All claims expressed in this article are solely those of the authors and do not necessarily represent those of their affiliated organizations, or those of the publisher, the editors and the reviewers. Any product that may be evaluated in this article, or claim that may be made by its manufacturer, is not guaranteed or endorsed by the publisher.

Copyright (c) 2021 Just, Poeplau, Don, van Wesemael, Kögel-Knabner and Wiesmeier. This is an open-access article distributed under the terms of the Creative Commons Attribution License (CC BY). The use, distribution or reproduction in other forums is permitted, provided the original author(s) and the copyright owner(s) are credited and that the original publication in this journal is cited, in accordance with accepted academic practice. No use, distribution or reproduction is permitted which does not comply with these terms. 